\title{
El concepto de espacio y el análisis regional
}

Daniel Hiernaux $N$. Alicia Lindon INSTITUTO MORACOLMEX

PRESENTACIÓN

I a elaboración del concepto de espacio tiene una larga trayectoria histórica dentro del pensamiento geográfico, y en la misma ha quedado estrechamente ligado al desarrollo del concepto de región, al menos de una determinada visión sobre la misma.

Históricamente el pensamiento geográfico comienza a vincular ambos conceptos en el último cuarto del siglo pasado, en el seno de la geografia clásica, tanto en su vertiente francesa (Vidal de la Blache y sus discípulos) como alemana (Hettner). Sin embargo, conviene tener presente que las conceptualizaciones del espacio hechas desde la geografia, datan de varios siglos atrás; incluso en un sentido muy general, la retrospección podría conducir hasta la figura del geógrafo griego Estrabón. En este sentido se puede recordar también que, ya hacia 1600, Bernardo Varenius planteó el tema al afirmar que la geografia se puede presentar como geografia general o como geografia especial. Así, si bien Varenius no hablaba de geografia regional ni de región, con su geografía especial sentó las bases para que tres siglos después se acuñara este concepto.

Sin embargo, cabe subrayar la importancia del cambio de paradigma producido a fines del siglo XIX, ya que 
es en ese tiempo cuando el pensamiento geográfico modela el concepto de región como la expresión de un espacio geográfico particular, y halla en el mismo una garantía de unidad ${ }^{1}$ para una disciplina como la geografia, que llevaba siglos debatiéndose entre unas supuestas ramas fisicas $y$ otras bumanas. Este nuevo concepto, el de región, en verdad nace al influjo de la visión de totalidad y unicidad con que los geógrafos decimonónicos influidos por el roman. ticismo alemán habían concebido al Cosmos o mundo. ${ }^{2}$

Así, a fines del siglo pasado la región se constituía en el espacio síntesis de las dimensiones natural y humana, $e$ incluso, para algunos géografos -representantes de la tendencia corológica ${ }^{3}$ la región debía ser el objeto de estudio de la disciplina, entre ellos, Alfred Hettner y Paul Vidal de la Blache, los principales representantes en

- La noción de garantía de unidad para la geografia debe entenderse en el contexto filosbfico del momento, en el que las ciencias se dividían en aquellas vinculadas a la naturaleza, y aquellas otras, conocidas como las ciencias del espíritu o del hombre. Asimismo, la idea de garantía de unidad es esencial en el interior de la geografia, que corría el serio riesgo de desaparecer tras una división interna en una geografía física y otra geografia bumana. Así, la región viene a presentarse como la posibilidad de una síntesis entre los fenómenos físicos y humanos que da unidad a un determinado lugar de la superficie terrestre.

${ }^{2}$ Se está haciendo particular referencia a Ale. xander von Humboldt, Karl Ritter y Elisee Reclus. Ortega Cantero, Geografia, 1987, pp. 3564.

${ }^{3}$ La tendencia corologica recorre el pensa. miento geográfico desde el siglo $x x$ y se ha caracterizado por estudiar la diferenciación de los lugares en la superficie terrestre. la geografía clásica alemana y francesa, respectivamente.

En este trabajo el objetivo no es analizar la evolución de estos dos conceptos dentro del pensamiento geográfico, por ello estas referencias sólo se hacen a modo de contextua. lización conceptual. En cambio, se intentará hacer una revisión de las principales conceptualizaciones del espacio desde visiones puramente filosóficas y económicas, para luego compararlas con las principales conceptualizaciones del espacio que actualmente se manejan desde la geografia. Todo ello tendrá un objetivo final que es analizar qué perspectiva puede ser más fructífera para el análisis regional.

A los efectos de partir de los niveles de mayor generalización, para luego descender a los conceptos más específicos, primero se presentan tres perspectivas distintas que corresponden a categorías de máxima generalización. Éstas son, las visiones del espacio continente o receptáculo, el manejo del espacio como reflejo, y finalmente, la que postula al espacio como una instancia o dimensión de la totalidad social. Posteriormente, se distinguen estas categorias según los aportes disciplinarios hechos desde la filosofia, la economía y la geografia, e incluso se plantean algunas diferenciaciones internas dentro de cada perspectiva disciplinaria.

Bajo la categoría de espacto receptáculo o continente, se están considerando aquellas conceptualizaciones que tratan al espacio como un mero soporte o sustrato sobre el cual se localizan elementos y relaciones; en otras palabras, como su nombre lo in- 


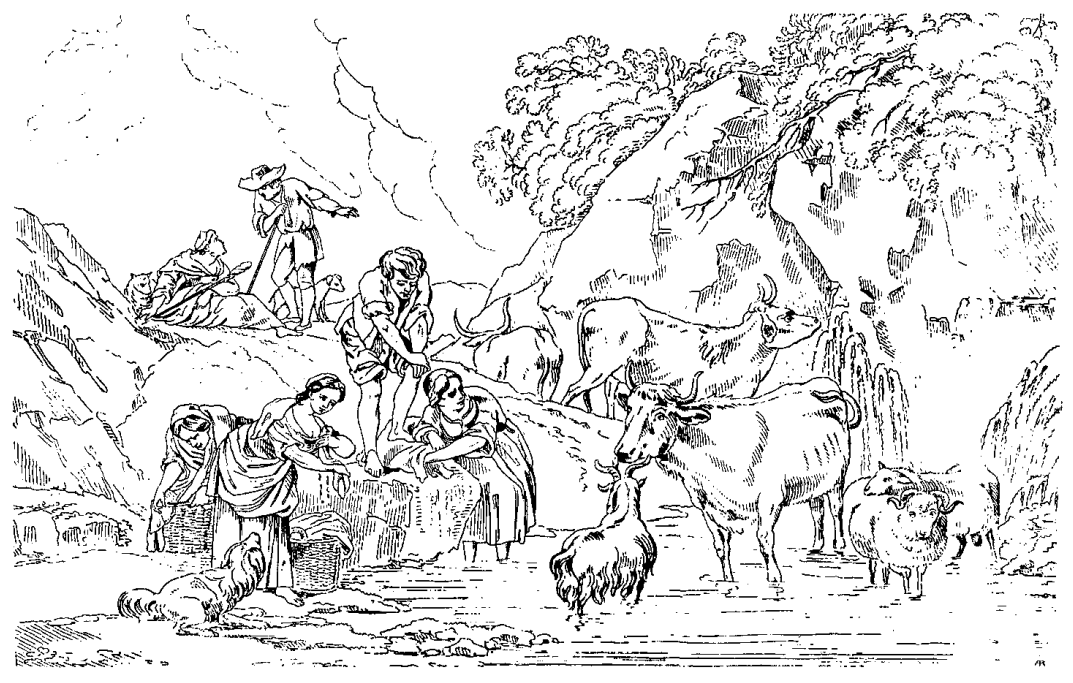

dica, el espacio contiene objetos. Bajo esta premisa, sólo es posible plantear relaciones unidireccionales, con lo cual el espacio pierde la posibilidad de ejercer cualquier influencia sobre los elementos y relaciones que en él se manifiestan. A lo sumo, en este espacio pueden expresarse relaciones entre los elementos, tales como la distancia, a su turno simplificable y medible en tiempo y costo.

De esta forma, en esta postura se incluyen tanto aquellas perspectivas para las cuales el espacio es continente en sentido empírico (las que tradicionalmente han sido definidas en es. tos términos), como también aquellas otras en las que la idea de continente sería a nivel mental y espiritual; en consecuencia, en este mismo agrupa- miento quedarían reuniclas las clásicas visiones economicistas que postulan la existencia de un espacio económico, para las cuales, el espacio es un receptáculo (o un plano homogéneo) en el que se implantan las relaciones económicas.

En cuanto al espacio como reflejo, nos referimos a aquellos enfoques para los cuales el espacio es casi un espejo de la sociedad y las relaciones sociales, es decir, que todo cambio social es reflejado inmediatamente y en forma directa en el espacio. En consecuencia, en esta perspectiva el espacio también es visto pasivamente, como algo capaz de reflejar cambios ocurridos en otras esferas de la vida social.

Respecto al espacio como estruc- 
tura $O$ instancia de la totalidad social, no se plantean distintos aportes disciplinarios convergentes en un mismo enfoque, ya que se trata de una línea conceptual desarrollada básicamente desde la geografia, y más específicamente desde la geografía crítica. No obstante, se podrían mencionar otros aportes que apuntan en esta misma dirección, sin tener una tan definida filiación disciplinaria, sino que más bien proceden de autores latinoamericanos identificados con la problemática regional y territorial, como Rofman o Coraggio.

En este enfoque, el espacio es entendido como una instancia o una estructura social integrante de la totalidad social, y como tal toma un carácter de estructura subordinantesubordinada, es productor y producido. Entonces, el espacio es una realidad objetiva mucho más allá de los particulares percepciones que de él puedan tener los individuos. En esta perspectiva, Milton Santos, su principal representante, ha rescatado la visión durkheimniana, según la cual el espacio es función de una sociedad al mismo tiempo que existe en sí mismo, y en este sentido se impone a la sociedad.

Asimismo, conviene aclarar que, al hablar de conceptualizaciones del espacio en términos filosóficos, se está haciendo referencia a aquellas reflexiones epistemológicas sobre el espacio hechas con instrumentos análíticos exclusivamente filosóficos, como es el caso de la respectiva reflexión kantiana. Ello no niega que cualquier intento de conceptualización, ya sea desde la economía, la geografia y otra ciencia, siempre se inscribe en una particular raíz filosófica.

Al abordar la problemática de la conceptualización del espacio desde estas tres categorías -continente, reflejo e instancia de la totalidad socialse pone de relieve la complejidad que supone dicha problemática. Así, se puede notar que posturas a veces enfrentadas, como las visiones materialistas dogmáticas y críticas, analizadas desde otros ángulos (por ejemplo, las tres categorías propuestas) presentan fuertes puntos de convergencia.

Frecuentemente, cuando se acude al concepto de espacio geográfico se hace sin más especificaciones que el atributo de geográfico, como si existiera una única conceptualización geográfica del espacio. Sin embargo, creemos que ello es insuficiente y encubre una diversidad muy grande. Por esta razón es necesario explicitar a qué paradigma geográfico se está haciendo referencia ya que la evolución del pensamiento geográfico, si bien nunca ha desplazado su eje de análisis del concepto de espacio, ha generado muy distintas formas de concebirlo.

\section{El ESPACIO CONTINENTE}

En este inciso se presentan las corrientes que consideran al espacio como continente o receptáculo, tanto desde la filosofía como desde la economía y la geografia.

\section{Desde la filosofía:}

En términos generales, cabe observar que todas las conceptualizaciones del 
espacio como receptáculo encierran el riesgo de dejar la posibilidad abierta de suponer que los objetos del mundo real puedan existir fuera del espacio. Estas visiones del espacio corresponden a lo que Lipietz ha denominado visión empirista del espacio ${ }^{4}$ Sin embargo, en algunos casos también se trata de visiones idealistas, aunque igualmente de tipo continente.

\section{a) Las perspectivas empíricas:}

En cuanto a las definiciones del espacio como continente, surgidas desde un enfoque puramente filosófico, conviene distinguir como posturas extremas, las que se ubican en la línca abierta por Aristóteles, continuada por Descartes y luego por Newton, en las cuales al hablar de espacio se hace referencia a un espacio absoluto, un espacio continente (en sentido empírico) en el cual no cabe la posibilidad de vacío. Para Aristóteles el espacio es un límite inmóvil que inmediatamente env'uelve a un cuerpo. ${ }^{5}$ Está presente la idea del continente, algo que rodea o que envuelve, aunque ese continente sea algo distinto del cuerpo mismo.

\section{b) Las perspectivas idealistas:}

La otra línea que conceptualiza al espacio en un nivel filosófico, es aquella que lo define en un orden men-

4 Lipierz, Capital, 1979, pp. 5-34.

5 vial Larrain, "Concepción", 1982, pp. 3031.

EL CONCEPTO DE ESPACIO Y EL ANÁLISIS REGIONAL tal; en ella se pueden ubicar, como principales representantes, a Hegel y a Leibnitz. Para el primero el espacio existe ante todo en el pensamiento, aunque Hegel reconoce que la naturaleza tiene existencia en sí misma, como un objeto, pero que depende del pensamiento para su construcción filosófica. ${ }^{6}$ Para Leibnitz, el espacio es un orden mental en el cual los cuerpos coexisten, y en consecuencia, cabe aquí la posibilidad de vacío; es decir que el espacio viene a constituirse en un sistema de relaciones, que existe independientemente de los individuos.

Esta última idea parece cercana a aquella otra de François Perroux, que entiende al espacio como "un campo de fuerzas", 7 ya que en niveles abstractos (como son estos dos en los que se está definiendo el espacio), se podría plantear que un campo de fuerzas es un sistema de relaciones.

En esta perspectiva, Henri Bergson ha señalado que el espacio no puede ser real, es decir "portar una existencia en sí misma, pues en verdad no hay cosas, las cosas no son más que visiones, aprehensiones de nuestro espíritu". ${ }^{8}$ En una línea de pensamiento más o menos cercana, se puede ubicar a Alfred Hettner, geógrafo alemán de mediados del siglo pasado, para quien el espacio no es más que una forma de percepción. Entonces, resulta clara la influencia kantiana de Hettner, inlluencia que también puede ser detectada en su concepción de región: la región es un espacio-tiempo único,

\footnotetext{
6 Santos, Pour, 1984, pp. 98-99.

7 Perroux, "Economic", 1964 , pp. 26-28.

8 Ibid., p. 97.
} 
por lo que el principal objetivo de la geografía sería precisamente, distinguir esas unidades o áreas diferenciadas de la superficie terrestre.

c) El puente entre el espacio del orden mental y el del mundo real

Tal como se ha podido ver, no es posible abordar el papel de la filosolia en la definición del espacio prescindiendo de las aportaciones de Kant; como tampoco es factible plantcar conceptualizaciones gcográficas (o cconómicas) del espacio, sin reparar en las bases filosóficas que las sustentan. $\Lambda$ juicio de diversos autores, como Vial Larrain, Kant intentó tender un puente entre las visiones del espacio absoluto (de Aristóteles y Newton) y las del espacio como orden mental (de Leibnitz y Hegel), al proponer una conceptualización del espacio que lo define como una condición de la posibilidad de existencia de los fenómenos, o sea una representación a priori, un fundamento necesario de los fenómenos externos. Según Vial Larrain, esa idea de pucnte entre las dos concepciones anteriores, se debe a que el pensamiento kantiano sostiene, por una parte, la iclea de espacio absoluto (aunque pase a ser definiclo como un "quantum infinito") y, por otra parte, si bien no se acepta la idea de orden mental, se asume la necesidad de una representación mental a priori. Lo particular de la perspectiva kantiana es que esta re-

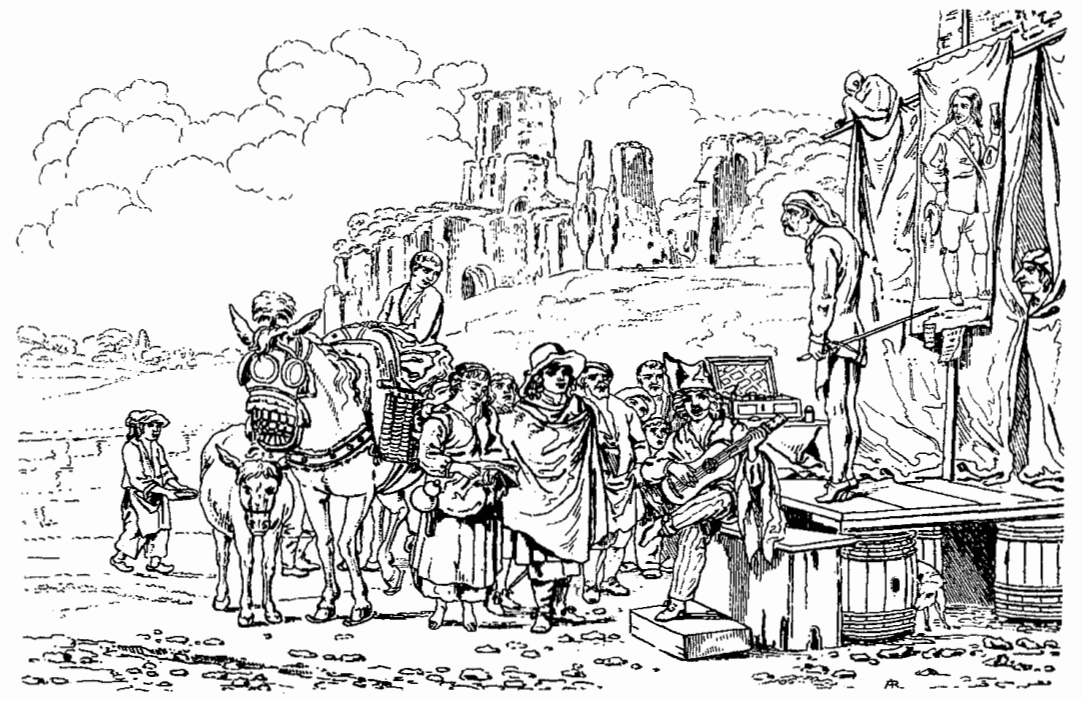


presentación necesaria no se daría en el nivel de la inteligencia, sino en el nivel de las sensaciones.

Así, el espacio sería una intuición pura, puesto que no es un concepto singular compuesto de sensaciones, sino que es "la forma fundamental de toda sensación externa",' con to que se estaría presentando una forma de conocimiento, y no un conocimiento en sí mismo. Por ello, este planteamiento quedaría en esa posición intermedia entre tas dos líneas de pensamiento anteriormente señaladas, ya que el espacio no sería ni un concepto sacado de la experiencia empírica -Newton-, ni un concepto intelectual -Leibnitz-, sino una intuición.

El hecho de que esta intuición sea a priori la está diferenciando de los objetos reales, y es una condición que existe a nivel sensorial más allá de la existencia empírica de los objetos. Entonces, la realidad empírica del espacio se da cuando esa intuición pura asume las formas específicas de los objetos reales. Con ello Kant reconoce la dimensión real del espacio (tal como postulaba Newton), pero también la dimensión ideal (de Leibnitz y Hegel), y separa en el tiempo la posibilidad de existencia de ambas.

La intuición a priori que se concreta en unos determinados objetos del mundo real, genera la intuición empírica; esta última tiene la característica de que siempre es única, porque cada espacio y cada tiempo le otorgan el carácter de único. Esta unicidad que Kant le atribuyó a cada 41.

9 Vial Larrain, "Concepcion", 1982, pp. 40- tiempo-espacio constituyó la influencia más fuerte que la concepción kantiana ejerció sobre el pensamiento geográfico. Su influencia es particularmente notoria en la escuela alemana hettneriana, y en su proyección en Estados Unidos a través de la obra de Richard Hartshorne. ${ }^{10}$ Dicha influencia kantiana en la geografía reabrió la siempre vigente discusión en torno a la cuestión de si el estudio de lo único es contrario a la posibilidad de formulación de leyes generales, con lo cual se pondría en tela de juicio el carácter científico de la disciplina misma." $\mathrm{Al}$ mismo tiempo, también sirvió para renovar el debate en torno a la posibilidad de homogeneizar los conceptos de único y singular.

En esta perspectiva teórica también se ubican las reflexiones de Georg Simmel, notablemente influido por Kant. ${ }^{12}$ Para Simmel el espacio es una condición de existencia, sin la cual los acontecimientos no pueden tener lugar. Desde el punto de vista social, el espacio no tiene relevancia, lo relevante radica en "el eslabonamiento y conexión de partes del espacio, producidos por factores espirituales". En este sentido, el espacio es "una actividad del alma, la manera que tienen los hombres de reunir, en intuiciones unitarias, los efectos sensoriales que en sí no poseen lazo alguno". ${ }^{13}$

De esta forma, el aporte de Simmel

10 Su principal obra: Hartshorne, Nature, 1939 , p. 658.

II Capel, Filosofia, 1981, pp. 314-365.

12 Aunque disciplinariamente la reflexión de Simmel en relación al espacio, en parte es filosófica y en parte es sociológica.

13 Simmel, Sociología, 1939, p. 208. 
parte de la reflexión kantiana, pero avanza y ubica el problema de la comprensión de espacio en relación cón la acción social, la acción recíproca en. tre los hombres. Así, si los sujetos vivieran aislados, sólo podrían "llenar" el espacio que ocupan materialmente, pero cuando los individuos se relacionan entre sí, el espacio que hay entre las personas toma sentido a partir de la acción recíproca que se establece entre los individuos. La relevancia que se le asigna al espacio es tal, que termina siendo lo que posibilita la acción recíproca entre los hombres. En relación a ello, Simmel encuentra que en alguna ocasión Kant definió al espacio como "posibilidad de coexistencia". ${ }^{14}$

Otra cuestión significativa en el análisis de Simmel sobre el espacio, es lo que denomina exclusividad del espacio, por cierto muy cercana a las preocupaciones de algunos geógrafos del siglo pasado y del presente. ${ }^{15}$ Simmel reconoce un único espacio general, del que cada espacio particular es un "trozo" único; por ello niega la posibilidad de pensar "en plural una parte del espacio localizada". ${ }^{16} \mathrm{En}$ este camino, el autor llega a asumir el carácter único de cada espacio o extensión territorial, y cuando un de. terminado organismo social se "confunde" con ese espacio constituye un todo único y exclusivo. El ejemplo que utiliza Simmel con relación al organismo social es el Estado, destacando

14 Ibid., p. 205.

is Nos referimos a la polémica entre lo único y lo singular, originariamente tratada por Hettner, aunque enfatizada entre Schaefery Hartshorne.

16 Simmel, Sociologia, 1939, p. 210. la imposibilidad de pensar un Estado sin un territorio asociado.

Esta reflexión simmeliana, aunque tiene sus bases en un espacio continente abstracto, cuando comienza a ser operativizada, termina siendo muy cercana a la concepción actual de la geografia crítica.

\section{Desde la geografía:}

No se puede mencionar que hacia principios de la década de los setenta, la geografia, al igual que otras ciencias sociales, se vio fuertemente influida por la psicología y la psicología social, generándose una corriente de pensamiento que es conocida como geografía de la percepción o del comportamiento. Al parecer esta forma de concebir el espacio tendria fuertes vinculaciones con la reflexión kantiana, en tanto nuevamente se vuelve a ubicar al espacio en el plano de las percepciones de los individuos, fucrtemente ligadas a las sensaciones. Por ello, la ubicación de esta corriente dentro de lo que se está denominando espacio receptáculo, se sustenta en el hecho de que en esta visión, el espacio contiene las personales formas de captarlo de cada individuo, mucho más allá de posibles objetividades.

Así para este enfoque, la definición de espacio geográfico aparece ligada, por un lado, a la simbología del espacio, y al mismo tiempo se le conceptualiza como "un conjunto de sentimientos, imágenes y reacciones con respecto al simbolismo espacial". ${ }^{17}$

17 Harvey, Urbanismo, 1977, pp. 1-33. 
Es notorio que en la misma época de los sesenta, se dicra una corriente de análisis espacial, fuertemente marcada por las percepciones, tanto en el pensamiento psicosociológico como en el análisis urbanístico, o en la antropología urbana. ${ }^{18}$ Se constata, en forma preliminar y a reserva de mayores precisiones, la relevancia que puede haber tenido el movimiento de la contracultura de los sesenta para el surgimiento de esta clase de conceptualizaciones. Cabe mencionar que desde la geografía, también existen otros aportes muy significativos, como los de Frémont, ${ }^{19}$ quien desarrolla la existencia de un espacio vivido como un espacio construido por cada sujeto a partir de vivencias particulares.

Para algunos autores, el espacio como simbólica o como percepción, es un proceso fuertemente marcado por la esfera individual, mientras que para otros es la combinación de esa dimensión individual con otra social, En esta última postura se ubican, entre otros aportes, los de una etapa reciente de la reflexión geográfica de David Harvey. ${ }^{20}$ Con respecto a la dimensión social se plantea la mediación de una serie de normas relacionadas con el orden social vigente, como condición para que un grupo de individuos llegue a crear una misma imagen del espacio. Es decir que, en la

18 Con respecto al pensamiento psicoso. ciológico relacionado con la percepción del espacio: Moles y Roemer, Psy'blologie, 1977. Para la perspectiva de la antropología urbana: Hall, Dimension, 1975; también Rappoport, Pour, 1972 , p. 207 . En función de un análisis más urbanístico: Linch, Liniage, 1971, p. 222.

19 Frémont, Region, 1976, p. 223.

20 Harvey, Consciousness, 1985, p. 293. formación de la representación mental del espacio, influirían tanto la experiencia individual, como las formas de socialización y por ende, la cultura, entre dichas formas.

Es evidente que en esta perspectiva cognoscitiva -la geografía de la percepción- se advierte una clara recuperación y revalorización de la dimensión "individual" en detrimento de la social. Como el mismo Harvey lo ha cuestionado posteriormente, este tipo de respuestas filosóficas frecuentcmente eluden la importancia cle las prácticas sociales que en cada tiempo conducen a la construcción de las formas espaciales, como si esas formas espaciales sólo surgieran de la praxis individual, y ésta fuera totalmente independiente de los condicionamientos sociales. De paso, conviene resaltar la operatividad que adquieren estos conceptos en el marco del avance de la ideología neoliberal.

\section{Desde la economía:}

Ia economía espacial y la teoría de la localización ${ }^{21}$ han producido concepciones de espacio económico que, en términos generales, se puede afirmar que conceptualizan al espacio como algo a priori, preexistente a la práctica, neutro, isotrópico, homogéneo, como un conjunto de puntos y distancias entre puntos sobre el cual se desarrollan $\rightarrow$ más exactamente, se despliegan o se implantanlas relaciones económicas.

En este concepto se observa que

21 Ponsard, Analyse, 1988, p. 452. 
para esta corriente, el espacio no sería más que un soporte. Esta conceptualización del espacio es totalmente funcional para el análisis neoclásico que, con escasas modificaciones de su patrón general de análisis, puede introducir este tipo de espacio en su análisis. Es en este senticlo que Milton Santos $^{22}$ también ubica a estas posturas, las que globaliza bajo la categoría de espacio continente, aunque cabe aclarar que Perroux sostuvo que hablar de continente y contenido es contradictorio en todo sentido con la vida moderna, por su carácter totalmente dinámico. Sin embargo, se puede entender que ese carácter de espacio neutro e isotrópico, no se refiere a otra cosa que a una abstracción de la realidad que opera exclusivamente como soporte o continente, en el sentido ya clásico que se le ha asignado anteriormente a este vocablo.

a) La perspectiva de Perroux:

En cuanto al concepto de espacio desarrollado por François Perroux, se puede comentar que sus fundamen. tos los halló, tanto en la definición de espacio rígido procedente de la geo. metría euclidiana, en la cual el espacio resulta a través de la ar ticulación de puntos, líneas y volúmenes, como en los conceptos de espacios abstractos provistos por la matemática moderna, para la cual hay tantos espacios como estructuras de relaciones abstractas que definen al objeto. A juicio de Perroux, la transposición de los dos con-

22 Santos, Pour, 1984 , pp. 97-109. ceptos de espacio (el de la geometría euclidiana y cl abstracto de la matemática moderna), pueden proporcionar en la disciplina económica tantos espacios económicos como estructuras de relaciones abstractas sean las que definan cada objeto de la ciencia económica. ${ }^{23}$

En ningún momento esta conceptualización del espacio tiene consideraciones territoriales, contrariamente a lo que se ha sostenido con posterioridad. Dicha dimensión territorial constituirá un agregado posterior al planteamiento original de Perroux, realizado inspirándose en el geógrafo Jacques Boudeville.

Las relaciones económicas entre elementos económicos pueden definir tres tipos básicos de espacios económicos, que son: 1) los espacios económicos definidos por un plan, 2) los espacios económicos definidos como un campo de fuerzas, y 3) los espacios económicos en tanto que agregados homogéneos. ${ }^{2 \cdot 4} \mathrm{Tal}$ como lo subraya acertadamente Palacios, ${ }^{25}$ no se trata de espacios en el sentido territorial, sino de visiones relativas al funcionamiento de la economía.

La definición de espacios económicos en términos de plan, no es otra cosa que una referencia a horizontes económicos, en los que entran las relaciones de una empresa con otras. Estas relaciones se miden con base en relaciones de oferta de insumos y compra de productos, y en las mismas son decisivas las funciones de precios y cos-

\footnotetext{
23 Perroux, "Economic", 1964, pp. 21-36.

2+ Boudeville, Problenis, 1966, pp. 1-21.

25 Palacios, "Concepto", 1983 , p. 60.
} 


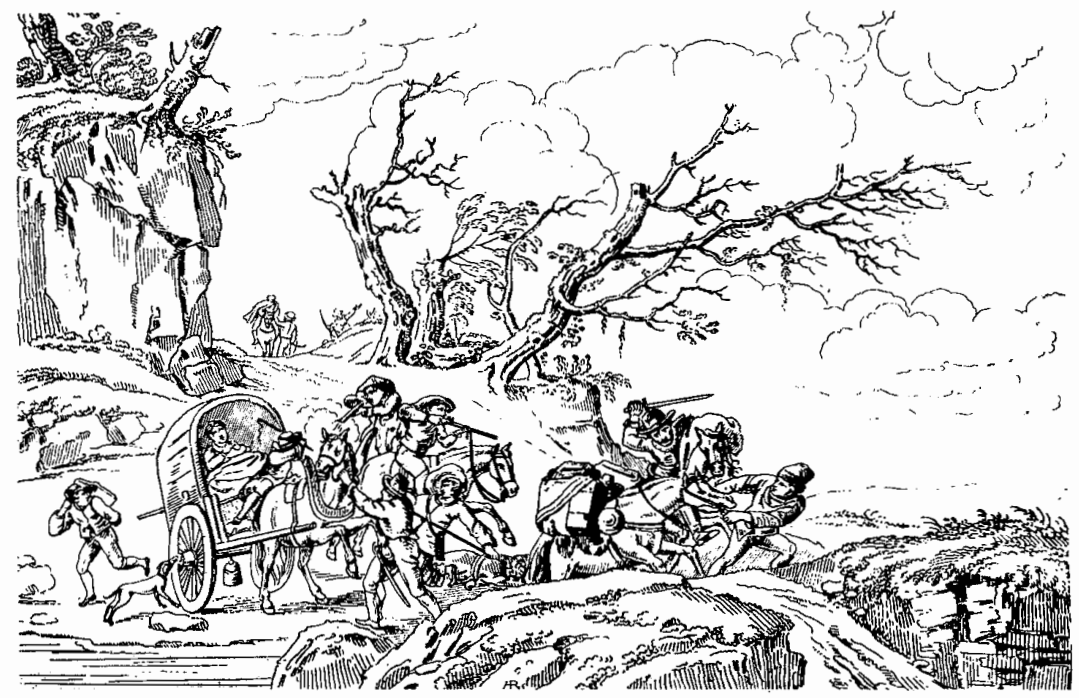

tos, que en última instancia marcan las distancias monetarias entre las empresas. Estas distancias monetarias determinan qué relaciones entre empresas son posibles, y por lo tanto, definen los planes, con lo cual se están definiendo espacios económicos.

La definición de espacios económicos como campo de fucrzas se funda en el supuesto de que tales espacios consisten en centros (o polos) desde los cuales se irradian fuerzas centrifugas y hacia los cuales se atraen fuerzas centrípetas. Entonces, cacla centro es un centro cle atracción y repulsión, que tiene su propio campo, su particular espacio de influencia. De csta forma, un espacio en una macroescala es el soporte de una red de polos que concentran recursos económicos.
Los planteamientos de Perroux sobre la posibilidad de definir el cspacio económico como un agregado bomogéneo, se refieren al espacio dado por una empresa o por un conjunto de empresas que tienen estructuras de producción semejantes y, en consecuencia, el espacio como agregado homogéneo sería el espacio doncle reina un determinado precio.

b) Las aportaciones de Boudeville:

La conceptualización de espacio económico de Perroux fue retomada por Boudeville, quien se encargó de enfatizar que el espacio económico no era lo mismo que el espacio matemático, ya que el primero se ge- 
nera por la aplicación de variables económicas (a través de procedimientos matemáticos y geométricos) a un espacio geográfico. Aunque esta afirmación plantea una duda, en cuanto a qué era el espacio geográfico en el entendimiento de Boudeville: si tal vez era topografía, o si se sugería una equiparación entre espacio geográfico y espacio geométrico.

De acuerdo con el esquema de Perroux, Boudeville desagrega el espacio económico en términos de bomogeneidad, polarización y planes. La homogeneidad la define por la descripción de ciertos niveles de similitudes, la polarización queda asociada con los flujos de insumos y productos y la dominación de ciertos puntos; y los planes, en tanto metas o fines, se definen en términos de políticas. De esta forma, Boudeville estaba definiendo los conocidos tres tipos de regiones: homogéneas, polarizadas (o funcionales) y planes o programas. En última instancia, siempre se trata de un espacio abstracto, discontinuo y capaz de ser afectado por cambios, que siempre fueron planteados ahistóricamente. Muchas veces se emplean estos conceptos de región desconociendo u omitiendo la esencia de esta tripología.

\section{EL. ESPACIO REFLEJO}

En relación a las caracterizaciones del espacio como reflejo, se pueden ubicar tanto algunas concepciones materialistas dialécticas de corte dogmático, como aquellas otras planteadas desde visiones no dogmáticas, como por ejemplo, por Castells y Lipietz; el común denominador de todas estas conceptualizaciones, sería el hecho de que el espacio queda subordinado a las otras instancias que operan en el funcionamiento de la economía y de la sociedad en general.

En cuanto a las consideraciones del espacio como reflejo, es decir, el espacio subordinado a las otras instancias, parece válido retomar el cuestionamiento de Milton Santos, respecto a la posibilidad de pensar en una economía que funcione sin bases geográfcas. Según este autor, sostener una postura semejante -como lo proponen indirectamente las posiciones referidas al espacio-reflejo- incluso resultaría contradictorio en el pensamiento marxista -del cual la mayoría de estas conceptualizaciones se reclaman herederas-, ya que Marx siempre otorgó la primacía a la totalidad. ${ }^{26}$

\section{Las perspectivas materialistas dogmáticas:}

Los planteamientos de Konstantinov serían un ejemplo de la visión materialista dialéctica del espacio, en su carácter más dogmático; básicamente sostienen que el espacio es "una forma real objetiva de existencia de la materia en movimiento. El espacio expresa la coexistencia de las cosas y la distancia entre ellas...".27 Esta cita demuestra claramente la referencia implícita al concepto de reflejo.

Konstantinov plantea que existe un

26 Santos, Pour, 1984, p. 115.

27 Konstantinov, Fundamentos, 1977, p. 82. 
nexo indisoluble entre la materia y el tiempo-espacio. Pero las formas espaciales dependen de la materia, lo que se manifiesta claramente cuando señala que "al cambiar las condiciones materiales, se modifican las formas espaciales", ${ }^{28}$ se asume una causalidad directa. Nuevamente, el espacio ha perdido capacidad para influir en los procesos sociales, es algo pasivo que, a lo sumo, puede reflejar a la sociedad. Esta forma de concebir el espacio ha quedado vinculada con la perspectiva geográfica que se ha focalizado en torno al desarrollo de la geografía física, si es que por un momento fucra válido hablar de una geogralía física.

\section{Las perspectivas materialistas críticas:}

En el enfoque del espacio reflejo también se pueden hallar una serie de reflexiones vinculadas estrechamente a la sociología urbana y a la teoría del capitalismo monopolista de Estado. En esta corriente vendrían a sumarse con matices y a veces con contradiciones implícitas y explícitas entre los distintos autores, diversos trabajos como los de Castells, Topalov, Lojkine, etcétera.

Del mismo modo, también son representativos de esta corriente del pensamiento espacial algunos trabajos de Alain Lipiez. Para este autor, el espacio, o mejor dicho, el cspacio socioeconómico, es un producto o reflejo de la articulación de las relaciones sociales. ${ }^{29}$ Aunque, parecería contradecir lo anterior cuando sos-

28 Ibial., p. 89.

29 Lipietz. Capital. 1979, p. 27. tiene también que "al mismo tiempo, en cuanto espacio concreto ya dado, como una limitación objetiva se impone a la expansión de esas relaciones sociales". 30

En el mismo sentido este autor, expresa que en "la reproducción social, el espacio material aparece ya como efecto, ya como determinante de esas relaciones". ${ }^{31}$ Estas últimas ideas parecerían clemostrar una fuerte contradicción interna en la conceptualización del espacio que realiza este au. tor. Esto hace que no sea posible clasificar su aportación en la corriente o perspectiva que ve al espacio como reflejo, por lo que se acercaría notablemente a los postulados de Santos, aunque posteriormente se acerca a la postura del espacio reflejo, cuando alirma que el espacio socioeconómico es una dimensión de las relaciones sociales. Estos giros contradictorios, parecen ser asumidos por el mismo $\mathrm{Li}$ pietz cuando explicita que, es "muy difícil escapar de la concepción empirista del continente". 32

EL. ESPACIO COMO UNA DIMENSIÓN DE LA TOTALIDAD SOCIAL, UNA PERSPECTIVA DESDE IA GEOgRAFía CRítica

Algunos autores, como Alain Lipietz, han planteado que el espacio social puede ser visto como "un momento en la reproducción social, y en este sentido el espacio es un renejo de las relaciones sociales". ${ }^{33}$ En

30 Ibid., p. 27

31 /bid. p. 28

32 Ibid., p. 28.

33 Ibial., p. 29. 
algunas ocasiones estos planteamientos han sido calificados como un error metodológico, ${ }^{34}$ a lo que tal vez se podría agregar teórico-metodológico. Esta crítica, surgida desde la geografia, se funda en que el espacio no puede ser entendido como un simple reflejo del modo de producción actual, en la medida en que también en la memoria de modos de producción anteriores que interactúan con relaciones sociales presentes.

En una perspectiva para la cual el espacio no es un mero reflejo de la sociedad, se pueden ubicar las reflexiones de Raymond Ledrut, ${ }^{35}$ sobre el

34 Trinca, "Organizacion", 1984, p. 87.

35 Ledrut, Fornte, 1984, p. 194. espacio como una estructura material de tipo alveolar o fragmentada. Esta estructura alveolar viene a constituir un conjunto de formas que median entre la sociedad y la naturaleza. En este sentido, una mediación entre la sociedad y la naturaleza, es el modo alveolar de a propiación de la naturaleza por parte del hombre. Estas formas especiales, por su misma fragmentación, permiten vincular niveles microsociales y macrosociales.

El alveolo es un espacio creado por el hombre y para ser ocupado por él, de modo que tiene una dimensión real y material, pero también está incorporado en las relaciones sociales. Esta perspectiva está presentando un espacio que termina siendo una parte de la

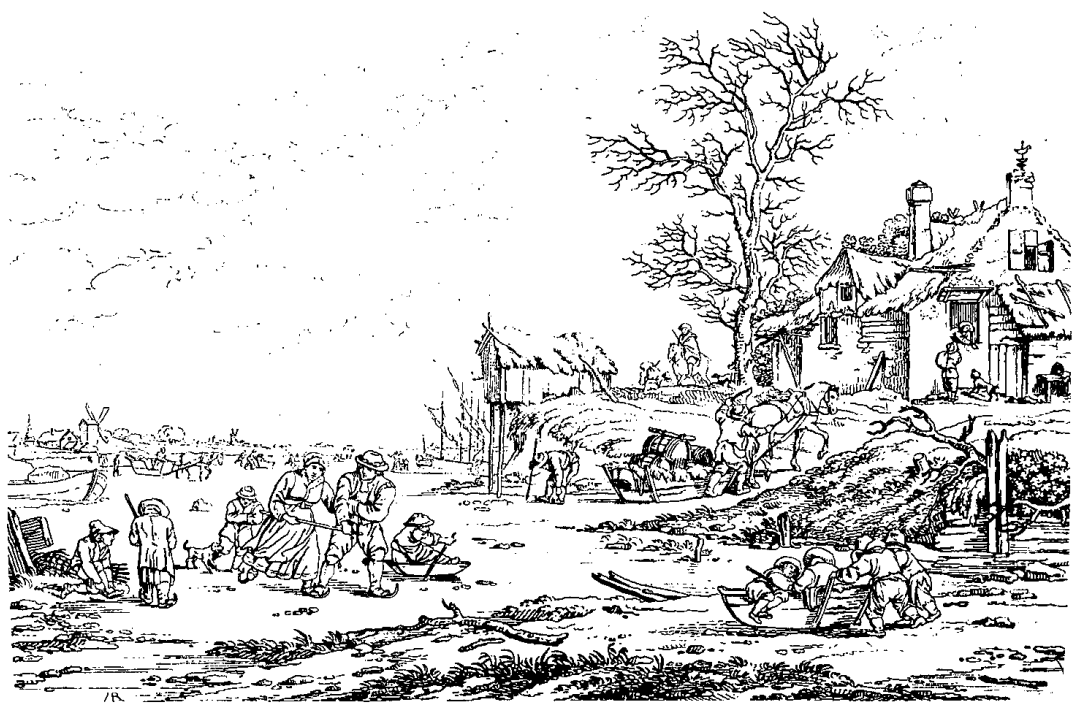


sociedad, en consecuencia, no puede ser una conceptualización del espacio como simple reflejo.

A continuación se toman las aportaciones de Milton Santos que, con la misma perspectiva recién comentada, ha desarrollado la conceptualización del espacio más representativa y acabada de la geografía crítica latinoamericana. Así, un concepto de espacio geográfico desde las conceptualizaciones desarrolladas por la perspectiva que ha dado en llamarse geografía critica, y siguiendo a Milton Santos, considera al espacio como un conjunto de relaciones que se desarrollan a través de funciones y de formas que representan una historia escrita por procesos del pasado y del presente.
Dicho en otros términos, el espacio se define como un conjunto de formas representativas de relaciones sociales del pasado y del presente y por una estructura que queda expresa en las relaciones sociales, a su vez indicativas de procesos y funciones. El espacio es atendido como un verdadero campo de fuerzas de intensidad y de velocidad desiguales, de lo cual se desprende el hecho de que su evolución no pueda ser igual en todas partes. ${ }^{36}$

Para este autor, una caracterización del espacio geográfico en estos términos, implica entenderlo como una forma, como un resultado objetivo de la interacción de múltiples variables en el curso de la bistoria, con lo cual

36 Santos, Pour, 1984, p. 95.

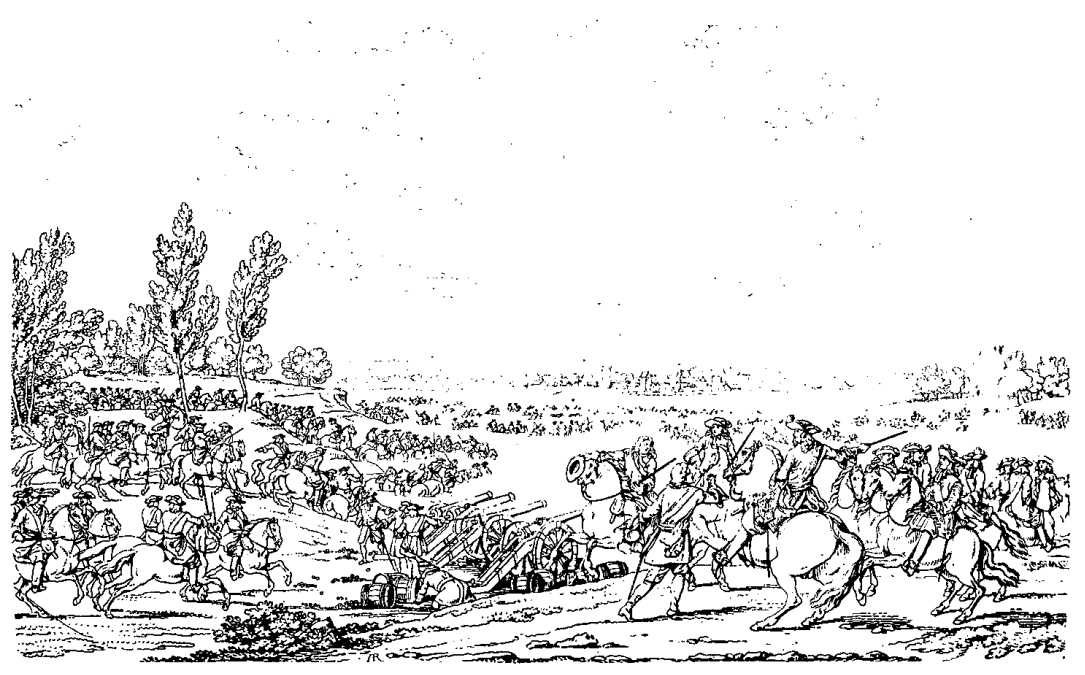

EL CONCEPTO DE ESPACIO Y EL ANÁLISIS REGIONAL 
se niega la posibilidad de entenderlo como una estructura subordinada a las otras estructuras (por ejemplo, la económica).

Así, la configuración geográfica o configuración espacial es la manera o arreglo espacial que adoptan los objetos que integran el espacio. Al mismo tiempo, la configuración espacial también es la esencia de esos objetos, es decir, es esencia en la medida en que responde a los procesos sociales que dan cuenta del arreglo de objetos que integran la configuración. Dichos procesos sociales se expresan como acciones sociales, y éstas se realizan a través de formas espaciales.

Los procesos sociales terminan adquiriendo un carácter geográfico ya que las acciones sociales se territorializan. En esa territorialización, el movimiento social -presente en cada acción social- se fija en un espacio y un tiempo. De esta manera, la formación de un espacio supone la acumulación de acciones localizadas en diferentes momentos. ${ }^{37}$

En esta visión el espacio es una instancia con autonomía relativa, al igual que las demás estructuras -económica, ideológica- que integran la totalidad social. Esto significa que la sociedad, como totalidad, está integrada por una serie de instancias, una de ellas es la espacial, las otras son: la económica y la ideológico-cultural. Esto tiene como consecuencia que la esencia de cada una de estas dimensiones, sea social; esto es, que la racionalidad que mueve a estas dimensiones es de carácter social.

37 Santos, Espaço, 1985, pp. 5-20.
Sin embargo, en el caso de la instancia espacial, por su misma naturaleza material y, en consecuencia, con capacidad de perdurar más que la socie. dad que produce las formas espaciales, tiene la posibilidad de influir sobre la totalidad social. Esto hace que el espacio pase a ser condicionante de los procesos sociales, lo cual no es contradictorio con la esencia social de la instancia espacial, ya que no se está pensando en un espacio sinónimo de naturaleza primera.

De esta forma, la geografía crítica está destacando dos cuestiones esenciales, una la cuestión de la historicidad, a través de sus formas, el espacio sobrevive al paso de los modos de producción. La otra, los condicionamientos que el espacio significa para el funcionamiento social global. Si el espacio fuera una estructura totalmente subordinada a las otras estructuras sociales, entonces tendría que experimentar cambios en forma simultánea con los cambios sociales, como un efecto de reflejo. Sin embargo la experiencia demuestra lo contrario, ya que las formas espaciales resultan resistentes al cambio, tal como ocurre con las formas jurídicas, que tienen una velocidad de cambio mucho más reducida que los procesos sociales. En buena medida, se puede afirmar que el pasado deviene en presente a través de las formas espaciales.

Esta característica es el fundamento mismo de la existencia del espacio como una dimensión de la totalidad social, y con capacidad de actuar reiteradamente sobre otras instancias de la sociedad. Un modo de producción nuevo, o nuevo momento 
de un mismo modo de producción no puede pasar por alto los condicionan. tes espaciales preexistentes, ${ }^{38}$ que sc le oponen e interactúan.

Esta posición no implica otorgarle autonomía absoluta al espacio respecto de la totalidad social. Ello significaría concebir al espacio y a las formas espaciales con existencia autónoma de lo social, o en otras palabras, se estaría cosificando al espacio. ${ }^{39}$ Por el contrario, se asume que tiene su esencia explicativa en la totalidad social, pero que también puede constituirse en determinante de lo social.

Así, una caracterización del espacio geográfico en estos términos, pucde resultar sumamente fructífera para el análisis regional, entre otras razones porque permite comprender el peso de las historias regionales o locales, que no necesariamente siguen siem. pre la racionalidad general, y que muy frecuentemente se constituyen en núcleos estructuradores de formas propias de poder local, que orientan las tendencias regionales. Todos estos planteamientos conducen al desarrollo del concepto de rugosidades, como espacio contruido, o como formas territoriales construidas, como tiempo histórico que deviene en paisaje (entendido como formas territoriales), como tiempo histórico incorporado en el paisaje actual. Este concepto remite a una división internacional del trabajo con significación local dada a través de particulares combinaciones de capital, técnicas y trabajo.

En esta visión el espacio viene a

${ }^{38}$ Santos, Pour, 1984, p. 114.

39 Coraggio, Territorios, 1987 , pp. $48-49$. constituirse en un testigo de un momento de un modo de producción, a través del espacio construido, de las cosas fijadas, del paisaje creado, una forma que no se deshace a medida que se desarrollan nuevos procesos, o nue. vas instancias de procesos anteriores. "Por el contrario, los procesos se adaptan a ciertas formas preexistentes, en tanto que otras se transforman en nuevas formas". ${ }^{40}$

Estas relaciones entre los procesos y las formas espaciales se pueden sintetizar en la expresión relactón sociedad-espacio, que a juicio de Antonio Moraes -siempre desde la geografía crítica- no sería otra cosa que una relación sociedad-valor mediatizada por el trabajo, ya que la sociedad, al apropiarse del espacio y modelarlo, crea valor en el espacio. ${ }^{41}$ Esas rugosidades de las que habla Santos vistas desde otro ángulo, también son valor en el espacio, y como tal tienen un senticlo histórico. Ahora bien, ese valor en cl espacio visto como espacio ya producido, hace referencia al valor del espacio, del que ya hablaban los geógra. fos franceses de principios de siglo.

Milton Santos al definir el espa. cio no sólo hace jugar el concepto de rugosidades, sino que también incorpora otro, sumamente esclarecedor, que es el de inercias dinámicas. Con lo cual expresa que el espa. cio organizado -para usar las palabras del géografo Jean Labasse- o las formas espaciales, si bien son rugosidades, es decir, son tiempo pasado constituido en formas territoriales actuales,

${ }^{40}$ Ibid., p. 108.

41 Moraes, Geografía, 1987, p. 123. 
también es inercia dinámica, es decir, el resultado de la interacción de múltiples variables presentes que ejercen condicionamientos o determinaciones -parciales- sobre los procesos sociales futuros. Estas inercias dinámicas se pueden manifestar de distintas maneras, por ejemplo, en la atracción que las grandes ciudades ejercen sobre la mano de obra potencial, en la atracción de capitales, etcétera.

Estos planteamientos pueden hacer pensar en el espacio producto, aunque implica un grado de complejidad mucho mayor, pero nunca podria llevar a la noción de espacio reflejo. Vale decir que, al mismo tiempo es resultado y es condicionante, por lo que incluso se podría hablar de espacio productor (sin que ello tenga ninguna referencia al determinismo geográfico).

Este enfoque está retomando y enriqueciendo la perspectiva señalada por Henri Lefevbre, quien sostuvo, por ejemplo, que el espacio no es un producto cualquiera entre los productos. Un punto en el que hay una clara correspondencia entre estas dos líneas de pensamiento, se halla a partir de la observación de Lefevbre acerca de que una de las contradicciones del espacio es que expresa al mismo tiempo lo efimero y lo estable, ${ }^{42}$ con lo que se podría hacer un paralelismo con las inercias dinámicas y las rugosidades de Milton Santos.

Dentro del enfoque que se ha denominado geografía crítica, también se ubican las reflexiones de Paul Claval -aunque con tesituras mucho me. nos innovadoras que las de Santos,

${ }^{42}$ Leferbre, Espacio, 1976, pp. 33-34. pero sí antecesoras-, de las cuales es apropiado considerar, en relación con la definición de espacio geográfico, la vinculación que este autor plantea entre espacio y poder. Posiblemente antes que ubicarlo dentro del paradigma de la geografía crítica, correspondería hacerlo en la instancia anterior, es decir, en la geografia activa, que sin duda sentó las bases para la posterior geografia crítica.

Claval trata de demostrar que el espacio puede ser subdividido o fragmentado para permitir el ejercicio del poder. "El espacio del poder puro requiere una organización ad boc del espacio, y necesita transferencias incesantes de información". ${ }^{43}$ Esta perspectiva merece ser tomada en cuenta para el análisis regional, ya que las formas de ejercicio del poder, al plantear subdivisiones del espacio (que generalmente se presentan como divisiones político-administrativas) imponen transformaciones en las condicio. nes sociales, económicas y territoriales, que pueden llegar a ser más poderosas de lo que usualmente se considera. Así también se debe reconocer que, en otras ocasiones, la identidad regional está tan profundamente definida que resulta muy escasamente modificada por esas subdivisiones del espacio, de las que se vale el ejercicio del poder.

El espacio y EL ANÁlISIS REgIONAL

En cuanto a las caracterizaciones del espacio geográfico de tipo tradicional,

${ }^{43}$ Claval, Espacio, 1982, p. 29. 
en donde sistemáticamente se confunde espacio geográfico con espacio natural -tal como se entrevé en la visión de Riesco- ${ }^{44}$ probablemente el aporte al análisis regional pueda ser muy limitado, porque a lo sumo proporciona algunos elementos que hablan de un soporte fisico sobre el cual se despliegan y desarrollan elementos y relaciones sociales.

Uno de los aspectos más peligrosos de este tipo de visiones es que, a cse sustrato físico -muchas veces llamado región- lo definen como un inventario de hechos físicos, que existen con total independencia de los fenómenos sociales, y en su carácter de soporte se constituyen en algo pasivo sobre lo cual la sociedad actúa. De esta forma se pierde la posibilidad de comprender un todo complejo en el que están profundamente articulados lo social y lo natural, articulación que, además, se redefine en cada tiempo histórico.

Asimismo, y sin pretender negar la carga simbólica que todo espacio geográfico posee, se puede observar que una conceptualización del espacio geográfico en función de las imágenes simbólicas con que los individuos se lo representan, probablemente pudiera ser poco útil para un análisis regional que se propusiera explicar el desarrollo histórico y la progresiva y desigual acumulación de trabajo en la superficie terrestre. Acumulación que desnaturaliza el espacio, al tiempo que lo complejiza, y que a las desigualdades naturales les sobreimpone otras desi-

H Ricsco, "Espacio", 1982, pp. 191-226. gualdades dadas por la diferencial fijación del trabajo.

La perspectiva del espacio marcada por los geógrafos radicales y críticos más ortodoxos, particularmente anglosajones, muy cercana a la negación de las raíces del pensamiento geográfico, parecería haber olvidado la subjetividad, a pesar de su revalo. rización de la ideología y del compromiso ideológico del sujeto de estudio; posiblemente la subjetividad se perdió al amparo de una racionalidad que muy difícilmente supera la dimensión económica. Además, en esta perspectiva analítica se ha priorizado la escala urbana, local y aun mundial, mas no la regional.

En cambio, un enfoque del espacio geográfico como el sostenido desde la geografia crítica latinoamericana, que encuentra sus raíces en la geografía radical francesa y que ha sabiclo rescatar mucho del pensamiento clásico, posiblemente sería más fructífero para el análisis regional. Sobre todo, si se trata de un análisis regional ubicado en la articulación de la escala global y la local e interesado en rescatar las acciones individuales con las cuales los sujetos toman decisiones frente a una estructura de opciones que se les presenta. Estas prácticas van construyendo el territorio objeto de estudio del análisis regional.

Un análisis regional de esta naturaleza es esencialmente un análisis del territorio, más específicamente de un recorte territorial que se identifica como región. Si la región es una realidad que carga en sus formas espaciales la huella de la modalidad con que 


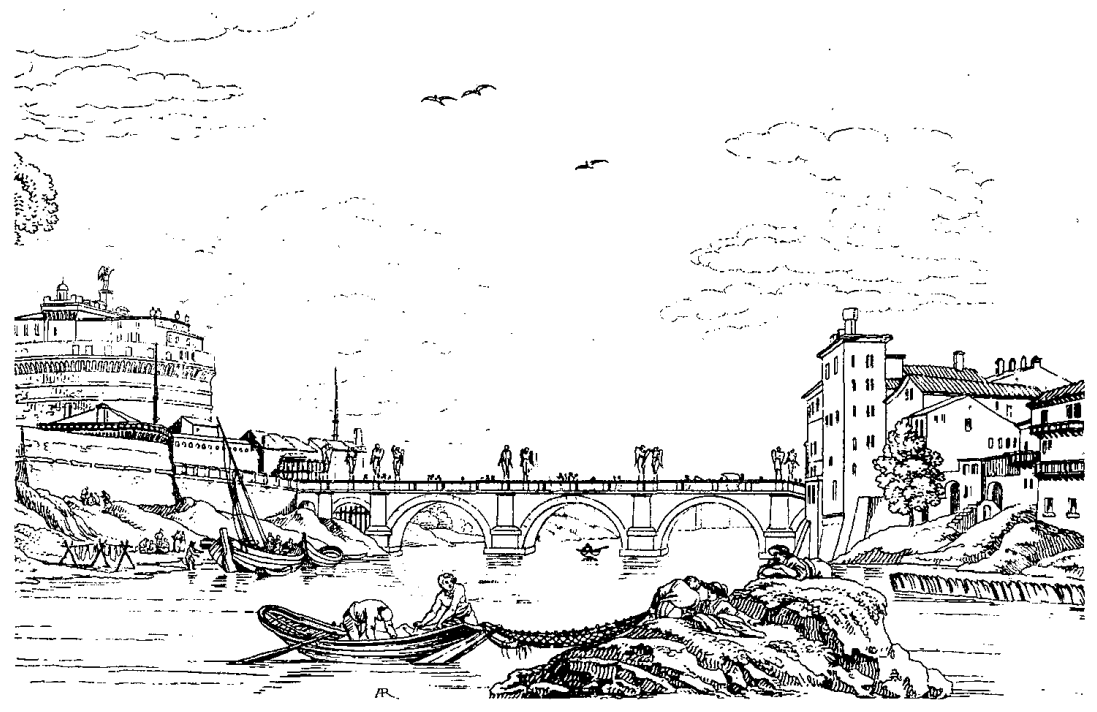

las formaciones socioeconómicas an. teriores y la presente han considerado el aprovechamiento del territorio, lo cual se traduce en esas formas espaciales únicas e irrepetibles (con lo que la región se hace pasado materializado en presente y también dinámica so. cietaria presente), entonces un análisis que vea la región en esta forma, es un análisis de un espacio geográfico particular. Espacio que no puede pensarse excluido de la tendencia expansiva de relaciones globalizantes, como las relaciones de producción capitalistas, que por el contrario, se basan en él, y también lo transforman continua. mente.

En este sentido, el análisis regional, tal como ha postulacto Pierre
George, ${ }^{45}$ debería buscar poner al descubierto contradicciones generadas por los sistemas de acumulación en los distintos cuadros regionales, es decir, denunciar las realidades espaciales injustas y contradictorias. Este análisis requiere de ejes conceptuales sobre la noción de espacio como los desarrollados desde la geografia crítica; ya que en última instancia $-y$ siguiendo a Doreen Massey- ${ }^{46} \mathrm{el}$ objetivo del análisis regional debería procurar entender los efectos de la diferenciación espacial.

45 George, Géograplie, 1964, p. 394.

46 Massey, "Regionalismo", 1981, pp. 50-83. 


\section{BIBLIOGRAFÍA}

-Boudeville, Jacques, Problems or regionat economics planning, University l'ress, Edimburgo, 1966.

-Capel, Holacio, rilosofia y ciencia en la geografía contemporánea, Editorial Barcanova, Barcelona, 1981.

- Claval, Paul, La evolución de la geografia bumana, Ed. Oikos-Thu, Barcelona, 1974, (Colección Ciencias Gcográlicas.)

- Espacio y poder, fondo de

Cultura Económica, México, 1982.

-Coraggio, Jose Luis, Terrilorios en Iransición, crútica a la planificación en Amévica Latina, Ciudad, Quito, 1987.

-Dauphiné, André, Espace, région ct systéme, Económica, París, 1979.

-Frémon, Armand, La régión, espace vécu, Presses Universitaires de France, París, 1976 (Colléction Sup. Le Géographe, 19).

George, Pierre, La geógrapbie active, Presses Universitaires de France, Paris, 1964.

-Gómez Mendoza, Josefina y otros, El pensamiento geográfico, estudio interprestativo y antología de textos (de Humboldt a las tendencias radicales), Editorial Alianza Universidad, Madrid, 1982 (Colección Textos, 15).

-Harvey, David, Urbanismo y' desigualdad social, Siglo XXI Editores, México, 1977.

, Consciousness and the ur. ban experience; studies in the bistory and tbeory of capitalism urbanization, Johns Hopkins University, Baltimore, 1985.

, The urbanization of capital; studies in the bistory and tbeory of capitalism urbanization, Johns Hopkins University, Baltimore, 1985.

Blackwell, Oxford, 1989.

-Hettner, Alfred, "La esencia y las funciones de la geografía", en Patricio Randle (comp.), Teoría de la geografia. Pri. mera parte, Sociedad Argentina de Estudios Geográlicos, Buenos Aires, 1977, pp. 80-105 (Scrie Especial, 4).

-Jannc, l lenri, "Lespace urbaine conçu comme projection de 'formes' (au sens de Raymond ledrut) sur le sol, traduites techniquement en structures "alvéolaires', en Espaces et Sociétés, núms. 57-58, 1990, pp. 147-157.

-Kant, Immanuel, Crítica de la razón pura, Editorial Losada, Buenos Aires, 19.13.

-Konstantinov, F. y otros, Fundamentos de filosofía maraista leninista, Ediciones de la Cultura Popular, México, 1977.

-Labasse, Jean, La organización del espacio, elementos de geografía aplicada, Instituto de Estudios de Administzación Local, Madrid, 1973.

-Ledrut, Raymond, La forme et le sens dans la société, Libr. des Méridiens, París, 1984 (Collection Sociologie des formes).

-Lefebvre, Henri, La produccion de l'espace, Editorial Anthropos, París, 1974.

Península, Barcelona, 1976.,

-Linch, Kevyn, L'image de la cilé, Dunod, París, 1971 (Collection Aspects de l'Utbanisme).

-Lipictz, Alain, El capital y' su espacio, Siglo XXI Editores, México, 1979.

-Massey, Doreen, "Regionalismo: algums problcmas atuais", en Espaço e Debates, núms. 3-4, 1981, pp. 50-83.

-Moles, Abraham y Elizabeth Roemer, Psychologie de l'espace, Casterman-Poche, Tournai, 1972 (Collection Mutations-Oricutation).

-Momes, Antonio, Geografía: pequeña bistoria crítica, Editora I lucitec, São Paulo, 1983.

- y otros, Geografia crítica. A valorização do espaço, Editora Hucitec, São Paulo, 1987.

-Ortega Cantero, Nicolás, Geografía y cultura, Alianza Editorial, Madrid, 1987.

-Palacios, Juan José, "El concepto de 
región: la dimensión espacial de los procesos sociales", en Revista Interamericana de Planificación, 1983.

-Perroux, François, "Economic space: theory and applications", Regional Development and Planning, MIT, Massachusets, 1964, pp. 21-36.

-Ponsard, Claude (dit:), Analyse economique spatiale, Press Universitaires de France, París, 1988 (Collection Economie).

-Rappoport, Amos, Pour une antbropo. logie de la maison, Dunod, París, 1972 (Collection Aspects de l'Urbanisme).

-Riesco, Ricardo, "El espacio en la geografía", El espacio en las ciencias, Editorial Universitaria, Santiago, 1982,

-Santos Milton, "Dimension temporclle et systémes spatiaux dans les pays du Tiers Monde", Revere Tiers Monde, t. XII, núm. 50, 1972, pp. 247-270.
, Pour une géograpbie nouve. lle (de la critique de la géograpbie a la géographie crilique), O.P.U., París, 1984. , O espaço e método, Editoral Nobel, São Paulo, 1985 (Coleçao Espaços). , O espaço do cidadao, Editorial Nobel, São Paulo, 1987 (Coleçao Espaços.)

-Simmel, Jorge, Sociología. Estudios sobre las formas de socialización, Editorial Espasa-Calpe, Buenos Aires, 1939.

-Trinca, Delfina, "Organización del espacio, ordenación del territorio", Revista Interamericana de Planificación, 1984, pp. 83-88.

-Vial Larrain, Juan de Dios, "Concepción filosófica del espacio", El espacio en las ciencias, Editorial Universitaria, Santiago, 1982, pp. 21-43.

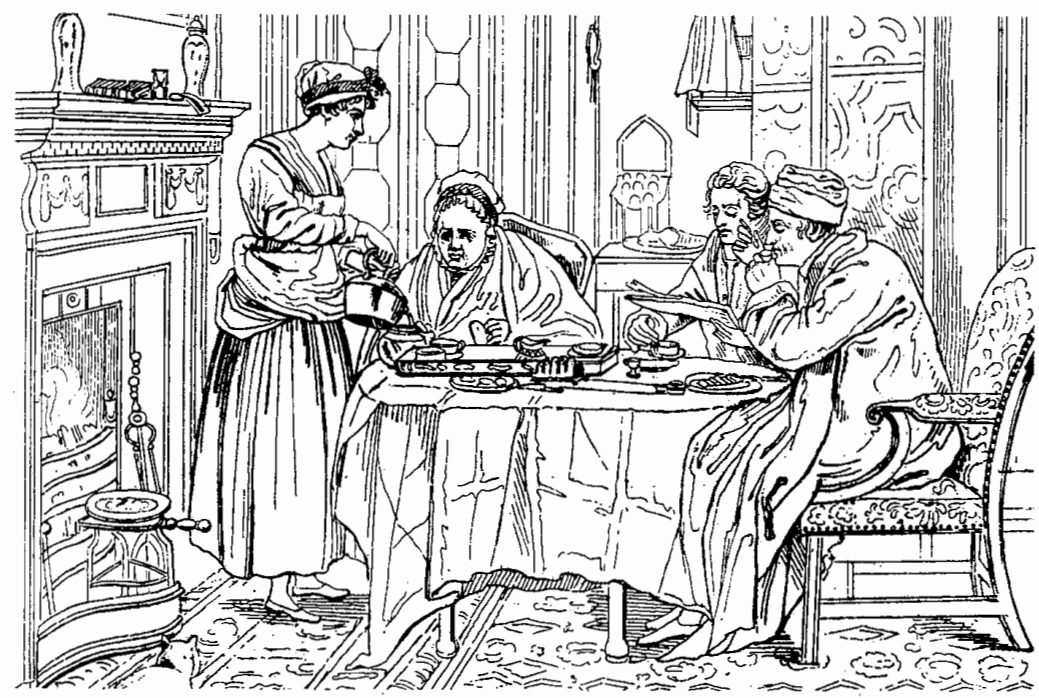

